\title{
Neuroendocrine syndrome in bronchial carcinoid tumors
}

\author{
CORNEL SAVU $^{1,2}$, ALEXANDRU MELINTE $^{2}$, JOSEPH LULA LUKADI $^{2}$, CRISTIAN MIRVALD $^{3}$, \\ CARMEN SAVU ${ }^{4}$, EMIL BELU $^{5}$, CAMELIA DIACONU $^{6,7}$, LAURA ILIESCU $^{6,8}$, IRINA BALESCU $^{9}$, \\ OVIDIU STIRU $^{10,11}$, OVIDIU BRATU ${ }^{12,13}$, GABRIEL GORECKI ${ }^{14}$ and NICOLAE BACALBASA ${ }^{15-17}$
}

${ }^{1}$ Department of Thoracic Surgery, 'Carol Davila' University of Medicine and Pharmacy, 020021 Bucharest;

${ }^{2}$ Department of Thoracic Surgery, 'Marius Nasta' National Institute of Pneumophtisiology, 050159 Bucharest; Departments of ${ }^{3}$ Urology and ${ }^{4}$ Anesthesiology, 'Fundeni' Clinical Institute; ${ }^{5}$ Department of Oncology,

'Prof. Dr. Al. Trestioreanu' Institute of Oncology, 022328 Bucharest; ${ }^{6}$ Department of Internal Medicine,

'Carol Davila' University of Medicine and Pharmacy, 020021 Bucharest; ${ }^{7}$ Department of Internal Medicine,

Clinical Emergency Hospital of Bucharest, 105402 Bucharest; ${ }^{8}$ Department of Internal Medicine,

'Fundeni' Clinical Institute, 022328 Bucharest; ${ }^{9}$ Department of Visceral Surgery, 'Ponderas' Academic Hospital,

021188 Bucharest; ${ }^{10}$ Department of Cardiac Surgery, 'Carol Davila' University of Medicine and Pharmacy,

020021 Bucharest; ${ }^{11}$ Department of Cardiac Surgery, 'Prof. Dr. C.C. Iliescu' Emergency Institute for

Cardiovascular Diseases, 022322 Bucharest; ${ }^{12}$ Department of Urology, 'Carol Davila' University of

Medicine and Pharmacy, 020021 Bucharest; ${ }^{13}$ Department of Urology, Emergency Central Military Hospital,

010825 Bucharest; ${ }^{14}$ Department of Anaesthesia and Intensive Care, 'Ilfov' County Emergency Hospital,

022104 Bucharest; ${ }^{15}$ Department of Obstetrics and Gynecology, 'Carol Davila' University of Medicine and Pharmacy,

020021 Bucharest; ${ }^{16}$ Department of Visceral Surgery, Center of Excellence in Translational Medicine

'Fundeni' Clinical Institute, 022328 Bucharest; ${ }^{17}$ Department of Obstetrics and Gynecology,

'I. Cantacuzino' Clinical Hospital, 030167 Bucharest, Romania

Received July 17, 2020; Accepted August 17, 2020

DOI: $10.3892 /$ etm.2020.9330

\begin{abstract}
Pulmonary carcinoid tumors represent bronchopulmonary neuroendocrine neoplasms which might synthetize serotonin, histamine, bombesin or other types of hormones

Correspondence to: Professor Nicolae Bacalbasa, Department of Obstetrics and Gynecology, 'I. Cantacuzino' Clinical Hospital, 5-7 Ion Movilă Street, 030167 Bucharest, Romania

E-mail: nicolae_bacalbasa@yahoo.ro
\end{abstract}

Abbreviations: APUD, amine precursor uptake and decarboxylation; bpNETs, bronchopulmonary neuroendocrine neoplasms; ACTH, adrenocorticotropic hormone; AVP, arginine vasopressin; ADH, syndrome of inappropriate antidiuretic hormone secretion; $\mathrm{MSH}$, melanocyte stimulating hormone; TNM, system tumor, node, metastasis; CT, computed tomography; MRI, magnetic resonance imaging; PET-CT, positron emission tomography; STAS, spread through air spaces; KEAP1, kelch-like ECH associated protein 1 gene; NFE2L2, nuclear factor, erythroid 2-like 2 gene; NFE2, nuclear factor, erythroid 2; Pro-GRP, progastrin releasing peptide; NET, neuroendocrine tumor; SRS, somatostatin receptor scintigraphy; Nd-Yag, neodymium-doped yttrium aluminum garnet

Key words: neuroendocrine pulmonary tumors, carcinoid, neuroendocrine syndrome, bronchopulmonary neuroendocrine neoplasms, bronchial tumors responsible for the development of a broad spectrum of signs and symptoms, known as carcinoid syndrome. Data of 98 patients submitted to surgery for bronchial carcinoid tumors in the Thoracic Surgery Clinic of the 'Marius Nasta' Institute of Pneumophtisiology between 2014 and 2018 were retrospectively reviewed. All patients were submitted to paraclinical tests, imagistic studies (computed tomography or magnetic resonance imaging), bronchoscopy and biopsy in order to have a positive diagnostic of pulmonary carcinoid. The most common clinical symptoms at the time of presentation were: Persistent cough followed by dyspnea and recurrent pulmonary infections. The main neuroendocrine syndromes found were Cushing and Carcinoid Syndrome. All patients were submitted to surgery with curative intent consisting of wedge resection (in 4 cases, $4.08 \%$ ), lobectomy (in 79 cases, $80.61 \%$ ), bilobectomy (in 5 cases, $5.1 \%$ ) and pneumonectomy respectively (in 10 cases, 10.2\%). In all cases neuroendocrine specific symptoms disappeared once the carcinoid tumor was removed. In conclusion, bronchial carcinoid tumors have a positive outcome in most cases. Specific neuroendocrine markers as well as neuroendocrine syndrome disappears once the tumor is removed.

\section{Introduction}

Carcinoid tumors are part of the neuroendocrine tumors APUD (Amine Precursor Uptake and Decarboxylation) 
originating in the Kulchitsky cells (agent affine cells). Pulmonary carcinoid tumors are part of bronchopulmonary neuroendocrine neoplasms (bpNETs) along with large and small cell pulmonary carcinoma (1). The first resection of this type of tumor was performed by Eloesser (2) through bronchotomy in 1939. The clinical syndrome associated with bronchial carcinoid tumors was first described by Stanford et al (3) in 1958. Arrigoni et al (4) described the atypical carcinoid as a histopathological form of bronchial carcinoid. Being a neuroendocrine tumor the bronchial carcinoid is capable of producing a variety of peptides and biological active hormones (5) thus leading to several endocrine syndromes.

Carcinoid syndrome is determined by secretion of serotonin along with histamine and bombesin. It can present with bronchoconstriction, flush, hemodynamic instability, tachycardia and accelerated digestive transit (6). Cushing syndrome is the second syndrome caused by carcinoid tumors and is determined by the ectopic production of ACTH (adrenocorticotropic hormone) (7). Another syndrome associated with bronchial carcinoid tumors is that of an inadequate secretion of AVP (arginine vasopressin) which may lead to sodium depletion and water retention. Inadequate secretion of $\mathrm{ADH}$ (syndrome of inappropriate antidiuretic hormone secretion) or inadequate secretion of MSH (melanocyte stimulating hormone) is two other examples of endocrine syndromes which occur in bronchial carcinoid tumors. Bronchial carcinoid tumors make up $10 \%$ of all carcinoid tumors and represent $4 \%$ of pulmonary tumors (8).

From a histological view there are two types of carcinoids: Typical and atypical carcinoids. Typical carcinoids are well defined and differentiated, less aggressive tumors, which are commonly located in a larger bronchus. Atypical carcinoids are more aggressive, less differentiated lesions, having a tendency to metastasize at the level of the local lymph nodes, liver, bones or brain. Atypical carcinoids are more common in elderly patients and most often located in the periphery of the lung. Staging of the bronchial carcinoid is done in the same manner as bronchopulmonary cancer using the TNM (tumor, node, metastasis) system. When it comes to typical carcinoids, which are considered less aggressive lesions, a clinical staging is used, the TNM system being only utilized in atypical pulmonary carcinoids.

The present study was approved by the Thoracic Surgery Clinic of the 'Marius Nasta' Institute of Pneumophtisiology (Bucharest, Romania). The aim of this study was to determine the frequency of bronchial carcinoid tumors associated with neuroendocrine syndrome as well as the frequency of symptoms associated with this type of pathology.

\section{Patients and methods}

A descriptive and retrospective study on a period of five years (2014-2018) was realized; the study included 98 patients who underwent surgery in the clinic with a confirmed diagnosis of bronchial carcinoid tumor. All patients included in the present study presented specific clinical syndromes (carcinoid or Cushing syndrome) and were submitted to paraclinical laboratory tests consisting of specific hormones urinary and plasmatic dosage, imagistic investigations (thoracic computed
tomography-CT, brain magnetic resonance imaging-MRI, chest X-ray), bronchoscopy and proved to have a histopathological diagnosis of typical or atypical carcinoid (Figs. 1 and 2).

The final diagnostic of carcinoid tumor was established on the specimens retrieved during bronchoscopy or on those which were obtained after surgical resection.

The most commonly encountered clinical manifestations were also monitored and correlated to the surgical procedure performed. In patients with neuroendocrine syndrome an ectopic secretion of ACTH was also investigated by dosing the plasmatic levels of ACTH, plasmatic and urinary cortisol; a suppression test with dexamethasone was also associated. In cases presenting carcinoid syndrome dosing of neuron-specific enolase marker, plasmatic and urinary serotonin were also performed. Diagnosis was further confirmed by several investigations: Chest X-ray, bronchoscopy, thoracic and superior abdomen CT, positron emission tomography (PET-CT) and pituitary gland MRI.

\section{Results}

Of the 98 patients 39 (39.79\%) were female and 59 (60.20\%) male. Patients were aged between 31 and 85 years with an average of 59.89 years. Distribution on age groups is as follows: $30-39$ years, 4 cases (4.08\%), $40-49$ years, 12 cases $(12.24 \%)$, $50-59$ years, 24 cases $(24.48 \%), 60-69$ years, 39 cases $(39.79 \%)$, 70-79 years, 15 cases (15.30\%), 80-89 years, 4 cases ( $4.08 \%)$.

From a histological point of view 68 cases $(69.38 \%)$ were typical carcinoids, of which 26 in women and in 42 men, and 30 cases $(30.61 \%)$ were atypical carcinoids of which 13 cases in women and 17 in men. Bronchoscopy revealed a normal bronchial tree in 9 cases $(9.18 \%)$ while in the remaining 89 cases (90.81\%) bronchial lesions specific to carcinoid tumors were found; in 29 out of the total number of cases (29.59\%) a bronchial biopsy was performed (Fig. 2). Neuroendocrine syndrome was found only in 5 out of the 30 cases of atypical carcinoids (16.66\%). When compared with the total number of cases of both typical and atypical carcinoid tumors, neuroendocrine syndrome was present in $5.1 \%$ of cases, in 4 females and 1 male. From these, 2 cases presented clinical manifestations of Cushing syndrome (two women aged 64 and 70 years, $2.04 \%$ ) and 3 cases with symptoms specific to carcinoid syndrome ( 2 women, 1 male). In 17 patients (17.34\%) the diagnosis was confirmed preoperative through bronchoscopy and biopsy of the tumor while in the remaining 81 patients $(82.65 \%)$ the diagnosis was established by the pathology examination of the excised specimen obtained after surgery. The most commonly encountered symptoms were represented by: Cough, 90 cases, dyspnea, 45 cases, recurrent pulmonary infections, 32 cases, hemoptysis, 27 cases, bronchospasm, 1 case, carcinoid syndrome, 3 cases, Cushing syndrome, 2 cases (Table I).

Association of two or more symptoms was also encountered: Cough with dyspnea and recurrent pulmonary infections in 32 cases and cough, dyspnea and hemoptysis in 27 cases.

Most bronchial carcinoid tumors were filed under stage Ia, 19 cases, $19.38 \%$ (tumor $<3 \mathrm{~cm}$, with no pleural invasion and without implication of the main bronchus, NOM0). 11 cases, $11.22 \%$ were stage IIb (tumor $<5 \mathrm{~cm}$, N1-mediastinal lymph nodes present, M0). Preoperatively only the patient with 


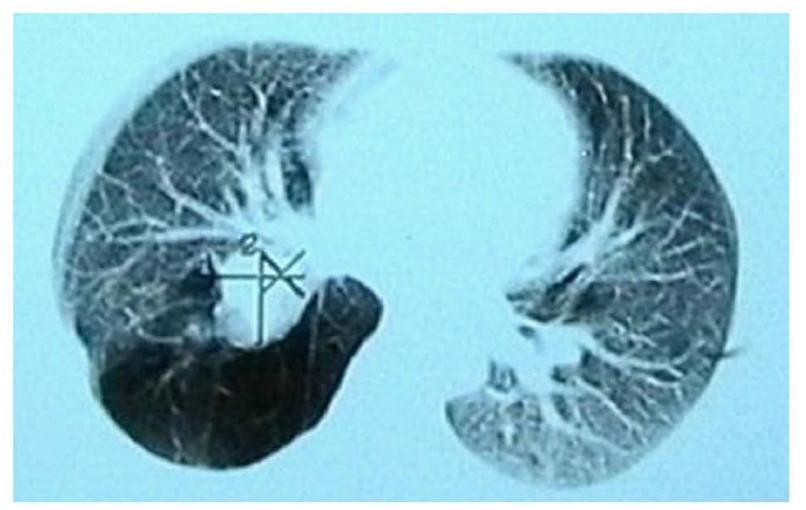

Figure 1. CT image of a bronchial carcinoid of the right superior bronchus.

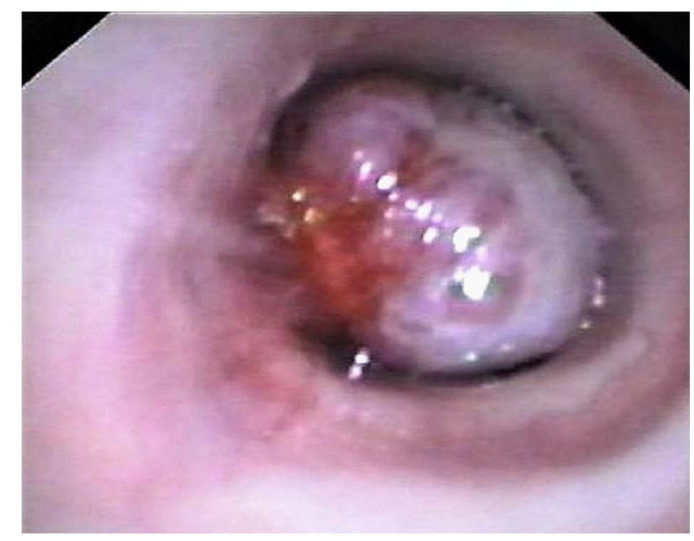

Figure 2. Bronchoscopical view of a carcinoid tumor in the left main bronchus.

Cushing syndrome was staged as IIb, but after surgery N1 was infirmed and the patient restaged to stage II a (T2bNOM0). The remaining cases of atypical carcinoid were staged as Ia and $\mathrm{Ib}$.

Cushing syndrome was present in a 64-year-old woman, smoker, from an urban area who was investigated for persistent cough and severe dyspnea. The patient was obese and presented with typical clinical signs: Purple stretch marks on the lower abdomen and thighs, thin skin. Imagistic investigations (chest $\mathrm{X}$-ray and CT scan) revealed the presence of a $3 / 4 \mathrm{~cm}$ mass in the right upper lobe associated with enlarged lymph nodes in the mediastinum (measuring $2.5 \mathrm{~cm}$ in diameter). Blood cortisol level was repeatedly measured at 00:00 and 9:00 a.m. with values between 700 and $900 \mathrm{nmol} / \mathrm{l}$ (reference value 130-600 nmol/l). Also $24 \mathrm{~h}$ urinary free cortisol was measured and demonstrated the presence of elevated values $2,350 \mathrm{nmol} / 24 \mathrm{~h}$ (reference value 100-380 $\mathrm{nmol} / 24 \mathrm{~h}$ ). Plasmatic ACTH was dosed in the same way and demonstrated the presence of elevated values 450 and $422 \mathrm{pmol} / 1$ (reference value: $2.2-17 \mathrm{pmol} / \mathrm{l})$. Dexamethasone test was negative. A pituitary MRI was performed in order to exclude the presence of a central cause for the hormonal imbalance but showed no pathological modifications. The final diagnosis was of a lung tumor in the right superior lobe associated with Cushing syndrome, classifying the lesion as a neuroendocrine tumor with ectopic secretion of ACTH.
Table I. Distribution of clinical manifestations in patients with carcinoid tumors.

\begin{tabular}{lr} 
Cough & 90 \\
Dyspnea & 45 \\
Recurrent pulmonary infections & 32 \\
Hemoptisis & 27 \\
Carcinoid syndrome & 3 \\
Cushing syndrome & 2 \\
\hline
\end{tabular}

Treatment was surgical and consisted in a right upper lobectomy with hilar and mediastinal lymphadenectomy. Pathology examination of the lobe identified a pulmonary atypical carcinoid tumor with no metastases in the lymph nodes. Postoperatively the serum hormonal levels normalized.

The second patient with Cushing syndrome was a 70-year-old woman with no smoking history, who presented for severe dyspnea and hemoptysis. Patient was obese and also associated skin hyperemia. The thoracic CT scan in association with bronchoscopy established the final diagnosis of bronchial carcinoid tumor within the inferior bronchus. Both morning and evening cortisol levels were elevated $(800-1,100 \mathrm{nmol} / \mathrm{l})$ as well as urinary cortisol, with values of 2,400 nmol/ h. Plasmatic ACTH was highly elevated: $743 \mathrm{pmol} / \mathrm{l}$. Surgery consisted in left inferior lobectomy with mediastinal lymphadenectomy; at one year follow-up the ACTH serum level was normalized.

Carcinoid syndrome was found in 3 cases $(3.06 \%)$, patients presenting with tachycardia, high blood pressure, flush, bronchospasm and an accelerated digestive transit. Diagnosis was further confirmed by 5 -hydroxyindoleacetic acid dosing (serotonin metabolite). This metabolite was found to be elevated between 25 and $43 \mathrm{mg} / 24 \mathrm{~h}$ (reference value $2-9 \mathrm{mg} / 24 \mathrm{~h}$ ). A $24 \mathrm{~h}$ urinary serotonin dosing also showed elevated values of up to $500 \mu / 24 \mathrm{~h}$ (reference value $50-250 \mu / 24$ h). Plasmatic serotonin levels were repeatedly dosed and were also found elevated (600-850 $\mu / 1)$ with a reference value of 80-400 $\mu / 1$. In all 3 cases neuron-specific enolase was also dosed and presented twice the reference values (reference value $<16 \mu / \mathrm{ml}$ ). All the laboratory findings together with imagistic investigations and bronchoscopy led us to the diagnosis of neuroendocrine pulmonary tumor with typical carcinoid syndrome manifestations. From a histological point atypical carcinoid was found in 30 patients $(30.61 \%)$ of which $5(5.1 \%)$ were associated with neuroendocrine syndrome.

All of the examined patients underwent surgery. Surgical treatment consisted of pulmonary resections ranging from wedge resection ( 4 cases, $4.08 \%$ ), lobectomy ( 79 cases, $80.61 \%$ ) of which: Lobectomy with lymphadenectomy (6 cases), bronchial sleeve resections (21 cases), bilobectomy (5 cases, 5.1\%), and pneumonectomy (10 cases, 10.2\%). Postoperatively in all cases the neuroendocrine syndrome disappeared at one month follow up. The long-term follow-up included performing chest $\mathrm{X}$ ray, thoracic CT and bronchoscopy at every six months while in cases diagnosed with atypical carcinoids with neuroendocrine syndromes PET CT was associated. 


\section{Discussion}

Bronchial carcinoid tumors have a rate of occurrence of 10-20\% out of all carcinoids, being rarer when compared with intestinal carcinoids (9). Atypical carcinoid tumor appears in $2 \%$ of all cases $(10,11)$, the mean age at diagnostic being 45-55 years. In our patients the average age was 59.89 years, however, for atypical carcinoids (30.61\% of cases) the average age was 51.5 years. Data from literature indicates that it occurs more often in females. In our group of patients the ratio of female to male was 1:2.26. In our study, bronchial carcinoid tumors were more often found in male patients rather than in female patients, as opposed to data found in literature. Location of bronchial carcinoids in $75 \%$ of cases is in the main respiratory tract (12).

In literature among the risk factors for developing a carcinoid tumor, smoking is mentioned (13). Of our patients 55 were smokers $(56.12 \%)$, but we cannot state with certainty that smoking would contribute to the development of bronchial carcinoid. It has been observed that this type of tumor is more common in Caucasians compared with other ethnic groups (14).

The differentiation of carcinoids in our group of patients was made by the pathology examination. An important parameter for differentiating carcinoids is considered to be the distribution of tumoral cells in the 'peritumoral aerian space' (STAS, spread through air spaces). According to this the presence of even one cell beyond the margins of the tumor would be suggestive. In typical carcinoids this phenomenon (STAS) appears in $48 \%$ of cases, whereas in atypical carcinoids it is present in $88 \%$ of cases (15).

In order to establish the diagnosing of carcinoid tumors an important role is played by immunohistochemistry, especially by Chromogranin A and Synaptophysin (16). Regarding this, some authors proposed the determination of a specific tumoral marker: Orthopedia homebox protein which would be specific for bronchial carcinoid, both typical and atypical (17). Another factor which may be considered a tumoral marker for cell proliferation is $\mathrm{Ki}-67$, thus having an important role in establishing an outcome (18). This factor is a mitotic index and a high number of $>10$ mitosis $/ 2 \mathrm{~mm}^{2}$ suggests that the tumor is a neuroendocrine carcinoid (17), whereas a number $<4$ mitosis $/ 2 \mathrm{~mm}^{2}$ would be suggestive of a typical carcinoid while a value $>4$ mitosis $/ 2 \mathrm{~mm}^{2}$ for atypical carcinoids. Previously atypical carcinoids were studied and alteration of the cellular genome ( 3 transcriptional subtypes with a specific genome alteration) similar to large cell bronchopulmonary carcinoma was observed. In carcinoid cells a degradation of the ratio between KEAP1 and NFE2L2 genes appears due to a promoter KEAP1 with effects on the hypermethylation process (19). It is known that KEAP1 during its interaction with NFE2 would dampen the oxidative stress of the cell (19). Also, in non-small cell bronchopulmonary carcinomas as well as pulmonary neuroendocrine tumors, an elevated level of Pro-GRP (progastrin releasing peptide) is found $(11,20)$.

A case of a bronchial carcinoid associated with Cushing syndrome and elevated Pro-GRP in relation with V1b (negative vasopressin receptor) was reported. With this data the authors proposed a new subtype of typical bronchial carcinoid (7). The American Clinical Oncological Society proposed the association of all neuroendocrine tumors, benign and malignant, under a new concept-NET (neuroendocrine tumor). There are 3 types of NETs in the lung: Carcinoid (typical and atypical), small and large cell bronchopulmonary carcinomas (21).

Carcinoid syndrome is found in $1-5 \%$ of cases and Cushing syndrome in $4 \%$ of cases of bronchial carcinoid $(18,22,23)$. In our study, carcinoid syndrome was found in 3 patients $(3.06 \%)$ and Cushing syndrome in two cases (2.04\%) of all bronchial carcinoids. The ectopic secretion of ACTH in cases with Cushing syndrome would be responsible for $10-15 \%$ of neurosecretant tumors $(24,25)$. Both Cushing and carcinoid syndromes appear in patient in the presence of liver metastasis when they are capable of ectopic hormonal production $(4,10)$.

Treatment for bronchial carcinoid tumors is complex, depending mainly on the histological type but also on the TNM stage. Most authors agree that if the tumor is resectable, surgical treatment is enough (26). Others consider that patients with mediastinal lymph node involvement must receive chemotherapy and radiotherapy in association with surgical resection $(4,27)$.

In our series of patients, surgical treatment varied and the type of performed resection was chosen based on location of the tumor, on the presence of secondary pulmonary suppurative reaction, associated neuroendocrine syndromes as well as on the presence of mediastinal lymph nodes. Therefore, anatomical resections were performed in $95.91 \%$ of cases while wedge resections were performed in only $4.08 \%$, this approach being allowed by the peripheral development of the tumor.

Regarding atypical carcinoids, we performed anatomical resections in 6 cases and wedge resections in 2 cases. The wedge resections where performed for tumors located peripherally with uncertain macroscopical or intraoperative histological examination. On the contrary the treatment for secretant atypical carcinoid tumors consist of anatomical resection associated with mediastinal lymphadenectomy (27).

Patients with stage III atypical carcinoid tumors must go through induction chemo- and radiotherapy. Bronchoscopy resections of endobronchial carcinoid tumors are only viable in selected cases while palliative treatment is reserved only for unresectable or metastatic tumors; in such cases chemotherapy and somatostatin administration might be taken into consideration $(28,29)$ Octreotide or Lanreotide might also be administered when the bronchial carcinoid has somatostatin receptors or if the patient presents hormonal symptoms. Somatostatin receptors may be observed through somatostatin receptor scintigraphy (SRS) $(30,31)$.

Previously, a Nd-Yag LASER was used for endobronchial resection of a typical bronchial carcinoid tumor located at the origin of the superior right bronchus (31); however, one year later surgical resection in the form of a bronchial sleeve lobectomy was performed.

In our series follow-up was done using mainly imagistic investigations (chest X-ray and CT) and also through bronchoscopy. In two cases PET-CT was used for patient that had atypical carcinoids with neuroendocrine syndromes. Recent studies have demonstrated that the factors which lead to a 
negative outcome are lymph node metastasis, the histological differentiation degree, location of the tumor (central or peripheral) as well as tumor size (32).

There are patients with bronchial carcinoids which presented with partial tumoral regression with no obvious explanation $(33,34)$.

In patients with carcinoid tumors in the absence of metastatic disease the 5 year survival rate is very high at $97 \%$, much higher than in other pulmonary tumors such as non-small lung cancer (35-37). In our study there were no recurrences or metastasis while paraneoplastic syndrome disappeared in all cases within the first month after resection.

Bronchial carcinoid tumors associated with neuroendocrine syndrome must be given surgical treatment similar to bronchopulmonary carcinomas no matter where they are located (central or periphery). In the short-term outcomes, neuroendocrine syndrome is expected to disappear shortly after surgery while a normalization of the serum markers is to be expected; in for the long-term outcomes, this histopathological subtype seems to be associated with a significantly better survival when compared with other histopathological subtypes of bronchopulmonary malignancies.

\section{Acknowledgements}

Not applicable.

\section{Funding}

No funding was received.

\section{Availability of data and materials}

The datasets used and/or analyzed during the present study are available from the corresponding author on reasonable request.

\section{Authors' contributions}

CoS performed the surgical procedures. AM, JLL and NB were part of the surgical team. AM, JLL, GG and IB prepared the manuscript. CM, OS, OB and $\mathrm{CaS}$ performed data analysis. CD and LI preoperatively examined the patients. GG, IB and EB conceived the study and drafted the manuscript. EB advised on the oncological outcome. CoS and NB revised the final draft of the manuscript. All authors read and approved the final manuscript.

\section{Ethics approval and consent to participate}

All patients read and signed the informed consent before participating in the study and before the publication of data.

\section{Patient consent for publication}

Not applicable.

\section{Competing interests}

The authors declare that they have no competing interests.

\section{References}

1. Peri M, Botteri E, Pisa E, De Marinis F, Ungaro A, Spada F, Grana CM, Gasparri R, Spaggiari L, Romentz N, Badalamenti G, Russo A and Fazio N: A single-institution retrospective analysis of metachronous and synchronous metastatic bronchial neuroendocrine tumors. J Thorac Dis 10: 3928-3939, 2018.

2. Eloesser L: Transthoracic bronchotomy for removal of benign tumors of the bronchi. Ann Surg 112: 1067-1070, 1940.

3. Stanford WR, Davis JE, Gunter JU and Hobart SG Jr: Bronchial adenoma (carcinoid type) with solitary metastasis and associated functioning carcinoid syndrome. South Med J 51: 449-454, 1958.

4. Arrigoni MG, Woolner LB and Bernatz PE: Atypical carcinoid tumors of the lung. J Thorac Cardiovasc Surg 64: 413-421, 1972.

5. Baudin E, Hayes AR, Scoazec JY, Filosso PL, Lim E, Kaltsas G, Frilling A, Chen J, Kos-Kudla B, Gorbunova V, et al: Unmet medical needs in pulmonary neuroendocrine (Carcinoid) neoplasms. Neuroendocrinology 108: 7-17, 2019.

6. La Rosa S, Volante M, Uccella S, Maragliano R, Rapa I, Rotolo N, Inzani F, Siciliani A, Granone P, Rindi G, et al: ACTH-producing tumorlets and carcinoids of the lung: Clinico-pathologic study of 63 cases and review of the literature. Virchows Arch 475: 587-597, 2019.

7. Yamamuro T, Inoue K, Nagai Y, Azuma D, Yamamoto A, Hara K, Kohara M, Iwata T, Nakatsuka S, Morii E and Yamamoto T: A case of ectopic ACTH syndrome due to DDAVP-sensitive but V1b receptor-negative bronchial typical carcinoid with lymphatic metastasis and plasma ProGRP elevation. Endocr J 65: 1161-1169, 2018.

8. Warren WH, Gould VE, Faber LP, Kittle CF and Memoli VA: Neuroendocrine neoplasms of the bronchopulmonary tract. A classification of the spectrum of carcinoid to small cell carcinoma and intervening variants. J Thorac Cardiovasc Surg 89: 819-825, 1985

9. Guenter RE, Aweda T, Carmona Matos DM, Whitt J, Chang AW, Cheng EY, Liu XM, Chen H, Lapi SE and Jaskula-Sztul R: Pulmonary carcinoid surface receptor modulation using histone deacetylase inhibitors. Cancers (Basel) 11: 767, 2019.

10. Garg R, Kumar R, Singh P and Kshetrimayum S: Atypical carcinoid tumor of the lung: A rare entity. Lung India 36: 236-238, 2019.

11. Grigoroiu M, Tagett R, Draghici S, Dima S, Nastase A, Florea R, Sorop A, Ilie V, Bacalbasa N, Tica V, et al: Gene-expression profiling in non-small cell lung cancer with invasion of mediastinal lymph nodes for prognosis evaluation. Cancer Genomics Proteomics 12: 231-242, 2015.

12. Betser L, De Wolf J, Glorion M and Chapelier A: Use of 3-dimensional computed tomography for planning a complex sleeve bronchoplasty with total parenchyma-sparing resection of a carcinoid tumour in the right main bronchus. Interact Cardiovasc Thorac Surg 29: 638-640, 2019.

13. Scoazec JY: Lung and digestive neuroendocrine neoplasms. From WHO classification to biomarker screening: Which perspectives? Ann Endocrinol (Paris) 80: 163-165, 2019.

14. Zabaleta J, Aguinagalde B, Lopez I, Laguna SM, Mendoza M, Galardi A, Matey L, Larranaga A, Baqueriza G and Izeta A: Creation of a multidisciplinary and multicenter study group for the use of 3D printing in general thoracic surgery: Lessons learned in our first year experience. Med Devices (Auckl) 12: 143-149, 2019.

15. Altinay S, Metovic J, Massa F, Gatti G, Cassoni P, Scagliotti GV, Volante M and Papotti M: Spread through air spaces (STAS) is a predictor of poor outcome in atypical carcinoids of the lung. Virchows Arch 475: 325-334, 2019.

16. Alrajhi NN, Paramasivam MP, Alboukai AA, Alrikabi AC and Alhamad EH: Diffuse idiopathic pulmonary neuroendocrine cell hyperplasia: Unusual presentation. Ann Thorac Med 14: 161-163, 2019.

17. Viswanathan K, Borczuk AC and Siddiqui MT: Orthopedia homeobox protein (OTP) is a sensitive and specific marker for primary pulmonary carcinoid tumors in cytologic and surgical specimens. J Am Soc Cytopathol 8: 39-46, 2019.

18. Grondahl V, Binderup T, Langer SW, Petersen RH, Nielsen K, Kjaer A, Federspiel B and Knigge U: Characteristics of 252 patients with bronchopulmonary neuroendocrine tumours treated at the Copenhagen NET Centre of excellence. Lung Cancer 132: 141-149, 2019.

19. Sparaneo A, Fabrizio FP, la Torre A, Graziano P, Di Maio M, Fontana A, Bisceglia M, Rossi A, Pizzolitto S, De Maglio G, et al: Effects of KEAP1 silencing on the regulation of NRF2 activity in neuroendocrine lung tumors. Int J Mol Sci 20: 2531, 2019. 
20. Tutar N, Yetkin NA, Yazici C, Onal O, Kontas O and Kelestemur F: Clinical significance of progastrin-releasing peptide, neuron-specific enolase, chromogranin a, and squamous cell cancer antigen in pulmonary neuroendocrine tumors. Turk J Med Sci 49: 774-781, 2019.

21. Tastepe AI, Kurul IC, Demircan S, Liman ST, Kaya S and Cetin G: Long-term survival following bronchotomy for polypoid bronchial carcinoid tumours. Eur J Cardiothorac Surg 14: 575-577, 1998

22. Shariff MZ, Curras-Martin D, Campbell N, Gupta V, Mikhail JD, Levitt MJ and Hossain MA: Carcinoid tumor of lung and BRCA mutation: A case report. J Med Case Rep 13: 132, 2019.

23. Cattoni M, Vallieres E, Brown LM, Sarkeshik AA, Margaritora S, Siciliani A, Filosso PL, Guerrera F, Imperatori A, Rotolo N, et al: Sublobar resection in the treatment of peripheral typical carcinoid tumors of the lung. Ann Thorac Surg 108: 859-865, 2019.

24. Wegner RE, Abel S, Hasan S, Horne ZD, Colonias A, Weksler B and Verma V: The role of adjuvant therapy for atypical bronchopulmonary carcinoids. Lung Cancer 131: 90-94, 2019

25. Benito-Martinez E, Galeano-Valle F, Gonzalez A, Edgar MA Oprea-Ilies G, Ioachimescu AG and Pasquel FJ: Ectopic ACTH syndrome with association of multiple pulmonary sclerosing pneumocytomas and multiple carcinoid tumorlets. J Endocr Soc 3: 937-942, 2019.

26. Dermawan JK and Farver CF: The prognostic significance of the 8th edition TNM staging of pulmonary carcinoid tumors: A single institution study with long-term follow-up. Am J Surg Pathol 43: 1291-1296, 2019.

27. Adrega T, Monteiro JP, Lareiro S, Guerra M and Vouga L: Surgical treatment of concomitant severe heart disease and lung cancer. Rev Port Cir Cardiotorac Vasc 26: 27-30, 2019.

28. Pelosi G, Massa F, Gatti G, Righi L, Volante M, Birocco N, Maisonneuve P, Sonzogni A, Harari S, Albini A and Papotti M: Ki-67 evaluation for clinical decision in metastatic lung carcinoids: A proof of concept. Clin Pathol 12: 2632010X19829259, 2019.

29. Torniai M, Scortichini L, Tronconi F, Rubini C, Morgese F, Rinaldi S, Mazzanti P and Berardi R: Systemic treatment for lung carcinoids: From bench to bedside. Clin Transl Med 8: 22 , 2019.
30. Rekhtman N, Desmeules P, Litvak AM, Pietanza MC, Santos-Zabala ML, Ni A, Montecalvo J, Chang JC, Beras A, Preeshagul IR, et al: Stage IV lung carcinoids: Spectrum and evolution of proliferation rate, focusing on variants with elevated proliferation indices. Mod Pathol 32: 1106-1122, 2019.

31. Inada $H$, Miyajima $K$, Imai K, Maeda J, Hagiwara M, Ito $T$ and Ikeda N: Bronchial typical carcinoid requiring left upper sleeve lobectomy after rigid bronchoscopic intervention. Kyobu Geka 71: 1097-1101, 2018 (In Japanese).

32. Reuling EMBP, Dickhoff C, Plaisier PW, Bonjer HJ and Daniels JMA: Endobronchial and surgical treatment of pulmonary carcinoid tumors: A systematic literature review. Lung Cancer 134: 85-95, 2019.

33. Kuwal A, Chauhan N, Dutt N, Elhence P, Advani M and Kumar S: Spontaneous partial regression of a carcinoid tumor: Radiology may not capture the real picture. Turk Thorac J 20: 153-156, 2019.

34. Uchida T, Matsubara H, Sugimura A, Matsuoka H, Ichihara T and Nakajima H: Spontaneous regression of a carcinoid tumor that required resection owing to its reappearance and subsequent enlargement after 2 years: A case report. Int Cancer Conf J 8: 58-60, 2019.

35. Brcic L, Heidinger M, Sever AZ, Zacharias M, Jakopovic M, Fediuk M, Maier A, Quehenberger F, Seiwerth S and Popper H: Prognostic value of cyclin A2 and B1 expression in lung carcinoids. Pathology 51: 481-486, 2019.

36. Dediu M, Horvat T, Tarlea A, Anghel R, Cordos I, Miron G, Iorga P, Alexandru A, Nistor C, Grozavu C and Savu C: Adjuvant chemotherapy for radically resected non-small cell lung cancer: A retrospective analysis of 311 consecutively treated patients. Lung Cancer 47: 93-101, 2005.

37. Galie N, Vasile R, Savu C, Petreanu C, Grigorie V and Tabacu E: Superior vena cava syndrome -surgical solution case report. Chirurgia (Bucur) 105: 835-838, 2010 (In Romanian). 